\title{
Eficacia y toxicidad de los antimoniales pentavalentes (Glucantime $®$ y Pentostam $®$ ) en un modelo animal de leishmaniasis cutánea americana: aplicación de la luminometría
}

\author{
Héctor Hernán Henao ${ }^{1}$, Yaneth Osorio ${ }^{1}$, Nancy Gore Saravia ${ }^{1}$, Arlen Gómez ${ }^{2}$, Bruno Travi ${ }^{1}$ \\ ${ }^{1}$ Centro Internacional de Entrenamiento e Investigaciones Médicas, CIDEIM, Cali, Colombia. \\ 2 Universidad Nacional de Colombia, Bogotá, D.C., Colombia.
}

Los antimoniales pentavalentes Glucantime $\AA$ y Pentostam $®$ son los medicamentos de primera línea usados en el tratamiento anti-Leishmania; sin embargo, no hay estudios in vivo que comparen su eficacia y toxicidad controlando variables del hospedero. Los estudios bioquímicos en Leishmania detectaron diferencias entre los dos medicamentos en la inhibición de la topoisomerasa I, que podrían reflejarse en diferencias en su efectividad. Para evaluar la eficacia clínica se infectaron hámsteres en la pata trasera derecha con $10^{6}$ promastigotes de Leishmania panamensis silvestre y transfectada con el gen de la luciferasa. Para evaluar la eficacia parasitológica se estandarizó la cuantificación de parásitos en los tejidos por luminometría. Tres semanas después de la inoculación, los animales se trataron intramuscularmente con Glucantime ${ }^{\circledR}$ o Pentostam ${ }^{\circledR}(30,60 \circ 120 \mathrm{mg}$ de Sbv/kg por día por 20 días). La toxicidad se evaluó en hámsteres tratados intramuscularmente con 120, 160 o $240 \mathrm{mg}$ de Sbv/kg por día por 20 días de Glucantime ${ }^{\circledR}$ o Pentostam ${ }^{\circledR}$. La resolución de las lesiones en los animales inoculados con ambas cepas fue similar con ambos medicamentos. La carga parasitaria disminuyó de forma equivalente con ambos medicamentos en todas las dosis, y resultó en diferencias significativas con respecto a los controles $(p<0,01)$. Los niveles séricos de creatinina, aspartato aminotransferasa, alanino aminotransferasa y amilasa no evidenciaron alteraciones hepáticas o renales. Los animales tratados con dosis iguales o mayores de $120 \mathrm{mg} \mathrm{de} \mathrm{Sb} / \mathrm{kg}$ por día por 20 días de Pentostam ${ }^{\circledR}$ presentaron alteraciones inflamatorias micro y

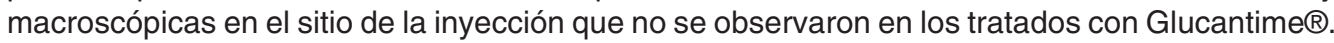
Estos resultados confirman observaciones clínicas sobre la eficacia similar de ambos productos e indican una toxicidad local mayor del Pentostam®.

Palabras clave: hámster, Leishmania panamensis, leishmaniasis/tratamiento, antimonio pentavalente, Glucantime $\AA$, Pentostam $®$, transfección, luminometría.

Efficacy and toxicity of pentavalent antimonials (Glucantime® and Pentostam $®$ ) in an American cutaneous leishmaniasis animal model: luminometry application

The pentavalent antimonial compounds Glucantime $\AA$ and Pentostam $®$ are the first line drugs used in anti-Leishmania treatment. However, no in vivo studies have compared the efficacy and toxicity of these drugs where host variability has been controlled. Biochemical studies of Leishmania have detected differences between the two drugs with regard to DNA topoisomerase I inhibition, a phenomenon that possibly impacts treatment efficacy. To evaluate the clinical efficacy, hamsters were infected intradermally in the right hind foot with $10^{6}$ promastigotes of a wild type or luciferase-transfected Leishmania panamensis. At three weeks post-inoculation, the animals were treated intramuscularly with either Glucantime $($ ) or Pentostam $\AA(30,60$ or $120 \mathrm{mg} \mathrm{Sb} / \mathrm{kg}$ per day for 20 days). To evaluate parasitological efficacy a luminometry assay was standardized for quantitation of amastigotes in hamster tissues. To evaluate toxicity, hamsters were treated intramuscularly with Glucantime $®$ or Pentostam $®(120,160$ or 240 mg SbV/kg per day for 20 days). Animals inoculated with either of the parasite strains and treated with either drug, showed a similar rate of lesion reduction, as compared to untreated controls $(p<0.01)$. 
Parasite burden was also comparable, and no significant differences were found in the cure rate. No renal or hepatic alterations occurred as evidenced by normal serum levels of creatinine, aspartate aminotransferase, alanine aminotransferase and amylase. Hamsters treated with $120 \mathrm{mg} \mathrm{Sb} / \mathrm{kg}$ per day for 20 days or higher doses of Pentostam $®$ showed macro- and microscopic signs of inflammation at the site of injection. These effects were absent in the animals treated with Glucantime®. The results confirmed clinical observations regarding the similar efficacy of the two drugs, as well as the higher local toxicity of Pentostam®.

Key words: hamster, Leishmania panamensis, leishmaniasis/treatment, pentavalent antimonials, Glucantime $®$, Pentostam $®$, luminometry, transfection.

Los antimoniales pentavalentes $\left(\mathrm{Sb}^{v}\right)$ durante medio siglo han sido la principal herramienta en el tratamiento de las diferentes formas clínicas de la leishmaniasis (1). Actualmente, se dispone comercialmente de dos formulaciones con $\mathrm{Sb}^{\mathrm{v}}$, el antimoniato de meglumina (Glucantime®) y el estibogluconato de sodio (Pentostam $\AA$ ) que se consideran equivalentes en términos de eficacia clínica, efectos secundarios, farmacocinética y mecanismos de acción (2-4).

Hasta el presente se han realizado pocos ensayos clínicos comparativos. Sáenz et al. (5) encontraron una eficacia clínica similar del Pentostam® y el Glucantime $®$ en pacientes con leishmaniasis cutánea producida por Leishmania panamensis usando una dosis diaria máxima de $850 \mathrm{mg}$ de $\mathrm{Sb}^{\vee}$ por vía intramuscular.

En otro estudio, Saldanha et al. (6) evaluaron la eficacia de los antimoniales pentavalentes Glucantime $®$ y BP88® (versión de fabricación china del estibogluconato de sodio) en pacientes infectados con Leishmania braziliensis, usando una dosis de $20 \mathrm{mg} \mathrm{Sb} / \mathrm{kg}$ pordía por 20 días por vía intramuscular o intravenosa de acuerdo con las posibilidades de aplicación. En ese trabajo, el porcentaje de curación para el Glucantime $₫$ fue de $62 \%$ y para el BP $88 \AA$ de $55 \%$, pero los pacientes tratados con Glucantime $₫$ resolvieron las lesiones más rápidamente. Infortunadamente, estos ensayos clínicos fueron de tipo abierto y realizados en una población heterogénea de

\footnotetext{
Correspondencia:

Bruno Travi, Centro Internacional de Entrenamiento e Investigaciones Médicas (CIDEIM), Avenida 1N No. 3-03, Cali, Colombia.

Teléfono: 668 2164; fax: 6672989

travib@ cideim.org.co
}

Recibido:13/07/04; aceptado: 22/09/04 pacientes, lo cual complica la interpretación de los resultados.

Los estudios de sensibilidad in vitro de cepas aisladas de pacientes sugieren que los medicamentos antimoniales pentavalentes tienen potencias distintas $(3,7)$. Sin embargo, debido a que los estudios comparativos se realizaron con cepas aisladas después del tratamiento, no era claro si las diferencias en la eficacia de los compuestos se debieron a una sensibilidad incrementada de algunos de los parásitos previamente expuestos a las drogas.

Grogl et al. (3) reportaron que en la mayoría de los casos los promastigotes aislados de pacientes que fallaron al tratamiento con antimoniato de meglumina tuvieron una concentración inhibitoria $50\left(\mathrm{IC}_{50}\right)$ mayor a este principio activo que al estibogluconato de sodio. Actualmente, se sabe que los promastigotes de Leishmania son altamente resistentes a los antimoniales pentavalentes (15), lo que en consecuencia resulta en una baja confiabilidad de las pruebas que usan $\mathrm{Sb}^{\vee}$ en promastigotes (8).

Otros factores como la variabilidad entre los lotes de medicamentos, los efectos citotóxicos de los aditivos, la diferente sensibilidad al $\mathrm{Sb}^{\vee}$ de las cepas de Leishmania y la respuesta inmune del hospedero han hecho difícil la comparación de los productos (7). Los estudios recientes sobre los mecanismos de acción anti-Leishmania del $\mathrm{Sb}^{v}$, enfocados a evaluar la inhibición de enzimas como las tirosín-fosfatasas (pTpasas) (9) y ADN topoisomerasa (10) han descrito diferencias en los efectos inhibitorios in vitro e in vivo entre los principios activos. La información bioquímica existente indica que el Pentostam $\AA$ y el Glucantime $®$ inhiben un rango distinto de $p$ Tpasas (9) y la topoisomerasa I sólo es inhibida por 
Pentostam $®$ y no por Glucantime $\circledR$ (10), pero se desconoce en qué medida estas diferencias influyen en la respuesta clínica al tratamiento.

Debido a la dificultad para controlar las variables relacionadas con el control del parásito por parte del hospedero en los estudios clínicos, el uso de modelos animales que aporten una respuesta homogénea es un recurso importante. El modelo hámster-L. panamensis ha sido usado con anterioridad para evaluar la respuesta al tratamiento con antimoniales en diferentes esquemas terapéuticos (11). En este modelo de leishmaniasis cutánea del Nuevo mundo, a diferencia del ratón, se obtienen lesiones crónicas similares a las observadas en humanos que responden al tratamiento con antimoniales (11).

La carga parasitaria es uno de los parámetros esenciales para evaluar la eficacia del tratamiento. Ésta se ha determinado hasta el presente por métodos laboriosos y poco sensibles como el cultivo por diluciones limitantes y el conteo de parásitos en frotis coloreados. Por esta razón, en este estudio se estandarizó y utilizó un método luminométrico para cuantificar los parásitos presentes en los tejidos después del tratamiento. La enzima luciferasa de la luciérnaga (Photynus pyralis) se está utilizando en forma creciente como gen reportero en distintas cuantificaciones biológicas a nivel celular (12). L. panamensis transfectada con el vector pGL2-aNEO-aLUC expresa la luciferasa constitutivamente, lo cual permite cuantificar los parásitos en una muestra utilizando un luminómetro (13).

En este estudio se evaluaron comparativamente la eficacia clínica y el efecto leishmanicida de dos presentaciones comerciales de $\mathrm{Sb}^{\mathrm{v}}$, usando el modelo hámster infectado con una cepa de $L$. panamensis transfectada con el gen reportero de la luciferasa. Además, se determinaron los efectos tóxicos de ambos productos.

\section{Materiales y métodos}

\section{Parásitos}

Se realizaron dos ensayos preclínicos independientes para evaluar la eficacia de los antimoniales. El inóculo consistió en promastigotes de fase estacionaria (día 6) de $L$. panamensis (MHOM/Col/84/1099) cultivados en medio de Schneider (Sigma) con 10\% de suero fetal bovino, $10.000 \mathrm{U} / \mathrm{ml}$ de penicilina $/ 10.000 \mathrm{mg} /$ $\mathrm{ml}$ de estreptomicina y $200 \mathrm{mM}$ de L-glutamina (Schneider completo). Esta cepa silvestre fue transfectada por electroporación con el vector episomal pGL2-aNEO-aLUC, construido en la Universidad de Laval, Canadá (13). Este vector le permite a la leishmania expresar constitutivamente el gen que codifica para la enzima luciferasa de la luciérnaga $P$. pyralis.

Los promastigotes transfectados se seleccionaron en medio de cultivo de Schneider completo con $80 \mu \mathrm{g} / \mathrm{ml}$ de geneticina G418 (Sigma) (13). Los parásitos que contenían el gen reportero se seleccionaron por su resistencia al antibiótico G418 y se inocularon en hámster para recuperar su patogenicidad. Un mes después de la infección los parásitos se recuperaron de las lesiones por aspirado y cultivo en medio de Seneckjie (agarsangre) y se seleccionaron nuevamente en medio de cultivo de Schneider completo con $80 \mu \mathrm{g} / \mathrm{ml}$ del antibiótico selectivo G418, para ser usados como inóculo.

Para determinar la carga parasitaria por luminometría se establecieron curvas de calibración con los parásitos recuperados de las lesiones 1 mes después de la infección como se muestra en la figura 1. Los estudios de estandarización anterior mostraron que los parásitos transfectados expresaron establemente el gen reportero de la luciferasa en los tejidos, sin presión de antibiótico G418, por un periodo de hasta dos meses. Después de este tiempo la correlación de las curvas disminuye, pero aún se logra la recuperación exitosa de parásitos transfectados hasta 6 meses después de la infección.

\section{Animales e infección experimental}

Se utilizaron hámsteres dorados (Mesocricetus auratus) exogámicos mantenidos en el bioterio del Cideim en condiciones estándar de alojamiento y nutrición, siguiendo las regulaciones de la Ley 84 de 1989 del Estatuto nacional de protección de los animales de Colombia y la Resolución 008430, del 4 de octubre de 1993. Los hámsteres hembra de 4-5 meses de edad, se inocularon intra- 
dérmicamente en la pata derecha con $10^{6}$ promastigotes de fase estacionaria de cultivo, empleando la cepa silvestre o transfectada con el gen de la luciferasa (MHOM/COL/84/1099pGL2aNEO-aLUC). Se escogieron animales hembra buscando disminuir la variación entre individuos, ya que son un modelo más homogéneo que los machos en el desarrollo de la lesión (14).

La cepa 1099 de L. panamensis se escogió por ser patogénica para este modelo animal y porque es relativamente resistente al tratamiento con $\mathrm{SbV}\left(\mathrm{EC}_{50}\right.$ en amastigotes $\left.>128 \mu \mathrm{g} / \mathrm{ml}\right)$ comparada con cepas sensibles $\left(E_{50}<10 \mu \mathrm{g} / \mathrm{ml}\right.$ ) (datos sin publicarse, Cideim); estas dos características permiten establecer la eficacia terapéutica comparativa usando dosis bajas y altas de $\mathrm{Sb}^{\mathrm{v}}$.

\section{Esquemas de tratamiento y evaluación de la eficacia clínica y toxicidad}

Tres semanas después de la inoculación con la cepa silvestre o transfectada los hámsteres fueron tratados por vía intramuscular durante 20 días con dosis de 30, 60 o $120 \mathrm{mg}$ de SbV/kg por día de Glucantime ${ }^{\circledR}$ (Rhodia Farma, S.P., Brasil, lote 108558) o Pentostam ${ }^{\circledR}$ (Glaxo Smith-Kline, lote A039752) ( $n=7$ por grupo), mientras que a un número similar de animales control se le administró solución salina tamponada (PBS) estéril siguiendo el mismo esquema. La dosis de $30 \mathrm{mg}$ de $\mathrm{Sb}^{\vee} / \mathrm{kg}$ por día de Glucantime ${ }^{\circledR}$ o Pentostam ${ }^{\circledR}$ no se incluyó en los inoculados con la cepa silvestre.

El tamaño de la muestra se determinó con base en los datos de patogenicidad y heterogeneidad de la lesión, obtenidos anteriormente para las cepas silvestre y transfectada (Cideim, datos sin publicarse). El tamaño de la lesión se midió con un calibrador digital como se ha descrito (11).

La eficacia clínica del tratamiento se expresó mediante un índice de evolución de la lesión: IE= tamaño de la lesión durante el tratamiento $(\mathrm{mm}) /$ tamaño de la lesión antes de iniciar el tratamiento $(\mathrm{mm})$. Los registros se efectuaron en los días 0 , 5,10 y 20 de tratamiento y a los 15 días después del mismo. Para la evaluación de la toxicidad producida por el tratamiento con los antimoniales, se usaron hámsteres $(n=6)$ tratados intramuscular- mente con 120, 160 o 240 mg de SbV/kg por día por 20 días de Glucantime $₫$ o Pentostam $\AA$.

Se determinó el estado clínico general de los animales por medio de la observación de signos (depilación, deshidratación, diarrea, poliuria) o síntomas (disminución de la ingesta, alteraciones del comportamiento) que indicaran toxicidad de las drogas empleadas. Se determinaron las concentraciones séricas de creatinina, creatinina cinasa (CK), aspartato aminotransferasa (AST), alanino aminotransferasa (ALT) y amilasa en el suero de los animales; se tomaron muestras de músculo esquelético en el sitio de la inyección del grupo de hámsteres tratados con $160 \mathrm{mg}$ de $\mathrm{Sb}^{\mathrm{V}} / \mathrm{kg}$ y se fijaron en formol tamponado al $10 \%$ para su posterior evaluación histopatológica. Los hámsteres se sacrificaron quince días después de completar el tratamiento.

\section{Evaluación de la eficacia parasitológica}

La eficacia de los $\mathrm{Sb}^{\vee}$ para eliminar el parásito se determinó en los hámsteres inoculados con las leishmanias transfectadas, quince días después de finalizar los tratamientos. Los amastigotes de Leishmania en las lesiones y el ganglio de drenaje del sitio de infección se cuantificaron por luminometría, siguiendo un procedimiento similar al descrito por Roy et al. (13), con algunas modificaciones en el método de lisis.

Se evaluaron diversos métodos de procesamiento de tejido: 1) el método estándar de triturado en nitrógeno líquido; 2) el triturado de la muestra en solución salina empleando mortero de vidrio con centrifugación a $6.000 \mathrm{rpm}$ por 10 minutos y posterior resuspensión en solución tampón de lisis, y 3) el triturado del tejido directamente en solución tampón de lisis a temperatura ambiente.

El último método que demostró ser el más eficiente, se describe a continuación: las biopsias de ganglio poplíteo y de piel del sitio de la inoculación se colocaron en $200 \mu$ lde solución tampón de lisis (BL) (Tris-HCl $125 \mathrm{mM}, \mathrm{pH} 7,8$, DTT $10 \mathrm{mM}$, glicerol al 50\% y Tritón X-100 al 5\%) y se homogenizaron con la ayuda de morteros plásticos para viales de $1,5 \mathrm{ml}$ (ganglio) o mediante el raspado y triturado de la dermis con hojas de bisturí. 
Los tejidos homogenizados se incubaron en $\mathrm{BL}$ durante 30 minutos a temperatura ambiente para almacenarlos a $-70^{\circ} \mathrm{C}$ hasta su procesamiento. $\mathrm{La}$ lectura de las muestras se realizó en un luminómetro (Lucy 1, Anthos-Labtec Instruments, Lagerhausstrasse, Austria), utilizando placas blancas de 96 pozos (Costar@) que contenían 25 $\mathrm{ml}$ de lisado y $80 \mathrm{ml}$ de solución tampón de ensayo (25 mM Tris-HCl solución tampón, pH 7,8, 2,67 mM MgSO4, 0,1 mM EDTA, 0,53 mM ATP y 33,3 mM DTT, 4,7 mM D-luciferina [Molecular Probes, Leiden, The Netherlands]).

Debido a la disminución progresiva en la actividad de luciferasa con respecto al tiempo, la solución tampón de ensayo se agregó inmediatamente antes de la lectura, evaluándose un máximo de 24 muestras por prueba. El límite de detección de la prueba y el número de parásitos por miligramo de tejido se determinó mediante la construcción de curvas de calibración a partir de la dilución seriada (1:10) de $10^{6}$ amastigotes obtenidos de la lesión de hámsteres con un mes de infección con la cepa L. panamensis MHOM/Col/84/1099 pGL2aNEO-aLUC, hasta obtener 1 parásito.

Las diluciones se mezclaron con 2,5 mg de tejido (piel sana) por pozo y se midió la actividad de la luciferasa con el luminómetro. Con estos valores, se obtuvo una curva de correlación, en escala

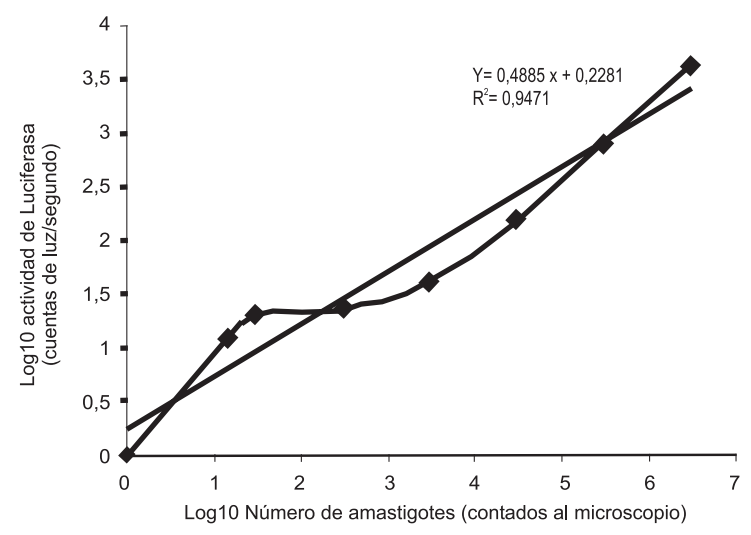

Figura 1. Curva representativa de la correlación entre el número de amastigotes de L. panamensis $\mathrm{MHOM} / \mathrm{COL} / 84 /$ 1099 transfectada con el vector pGL2-aNEO-aLUC (13) contados en las lesiones de hámsteres al mes después de la infección (microscopía) y la actividad de la enzima luciferasa (luminometría). logarítmica $\left(\log _{10}\right)$, entre el número de parásitos contados al microscopio de luz y la actividad de luciferasa de los mismos determinada en el luminómetro (figura 1).

El número de parásitos se despejó de la ecuación de la curva de calibración $Y=m X+b$; de donde $Y=\log _{10}$ (actividad de la enzima luciferasa en la muestra), $X=\log _{10}$ (número de parásitos), $m=$ pendiente y $b=$ constante de la ecuación (intercepto) (figura 1). El blanco del ensayo se estableció con base en la emisión de luz de muestras de tejido no infectadas (media +3 desviaciones estándar). El número mínimo de parásitos detectados se calculó restando el blanco del ensayo al valor de la actividad de luciferasa, utilizando la ecuación de la recta descrita en la figura 1.

\section{Análisis estadístico}

Para el análisis de los datos se utilizó el paquete estadístico SPSS, versión 7,5 para Windows (SPSS Inc., Chicago). A los datos con distribución normal se les aplicaron las pruebas t de Student y ANOVA, y como indicador de tendencia se usó la media. Las comparaciones múltiples se realizaron mediante las pruebas de Duncan y Tukey. Los datos cuya distribución no fue normal se analizaron mediante pruebas no paramétricas como Mann-Whitney y Kruskal-Wallis y se usó la

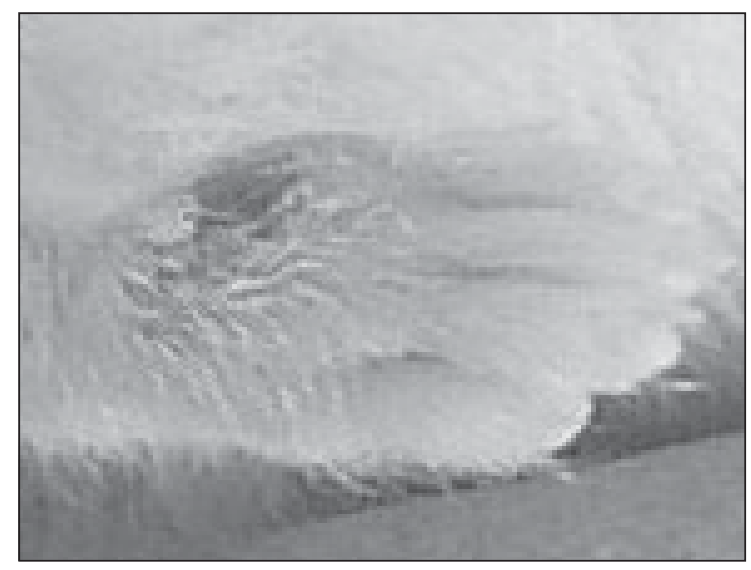

Figura 2. Aspecto clínico de la lesión en la pata trasera del hámster hembra un mes después de la infección producida por $10^{6}$ promastigotes de L. panamensis $\mathrm{MHOM} / \mathrm{COL} / 84 /$ 1099 transfectada con el vector pGL2-aNEO-aLUC (13), que contiene el gen reportero de la luciferasa. 
mediana como indicador de tendencia. En todos los análisis se utilizó un intervalo de confianza del $95 \%$.

\section{Resultados}

\section{Eficacia clínica del tratamiento}

La infección con promastigotes de L. panamensis de ambas cepas (silvestre o transfectada con el gen de la luciferasa) produjeron lesiones eritematosas con signos locales de inflamación, descamación y alopecia en el sitio de la infección (figura 2). En algunos animales se observó la aparición de costras como signo de necrosis dérmica. El tamaño promedio de las lesiones a las tres semanas de la inoculación en los hámsteres hembra inoculados con la cepa silvestre fue de $1,5 \pm 0,5 \mathrm{~mm}$ y en las inoculadas

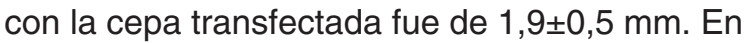
los inoculados con la cepa transfectada, la dosis de $30 \mathrm{mg}$ de $\mathrm{SbV} / \mathrm{kg}$ demoró más de 10 días en mostrar efectos terapéuticos con ambos productos, pero al finalizar el tratamiento tanto el
Glucantime $₫$ como el Pentostam $₫$ mostraron diferencias clínicas significativas con respecto al grupo no tratado (figura 3A). La disminución de las lesiones fue más rápida y acentuada con los esquemas de 60 y $120 \mathrm{mg}$ de SbV/kg, lo cual demuestra un efecto dosis-respuesta similar para ambos productos en los grupos inoculados con la cepa silvestre y transfectada (figura 3B y 3C).

\section{Eficacia parasitológica del tratamiento}

Correlación entre la actividad de luciferasa y el número de parásitos y su límite de detección. Para poder hacer las determinaciones del efecto antiparasitario de los antimoniales fue necesario estandarizar la técnica luminométrica para cuantificar los parásitos transfectados en los tejidos que serían evaluados (piel y ganglio). En el proceso de estandarización se obtuvo una correlación lineal $\left(R^{2}=0,94\right)$ entre el número de amastigotes de las lesiones, (determinado por microscopía de luz al mes de la infección) y la actividad del gen reportero de luciferasa (cuentas
(A) $30 \mathrm{mg} \mathrm{SbV}$

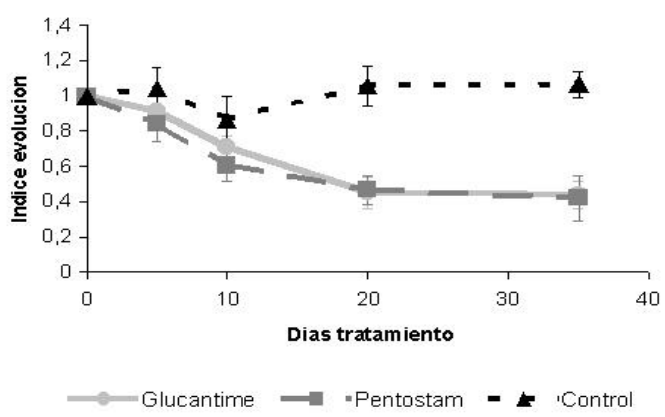

(C) $120 \mathrm{mg} \mathrm{SbV/Kg}$

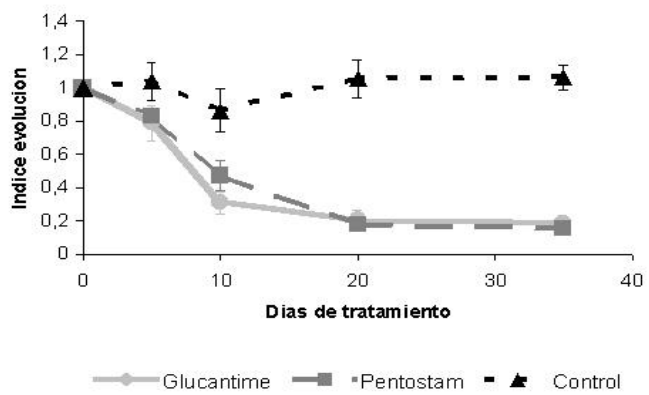

(B) $60 \mathrm{mg} \mathrm{SbV/Kg}$

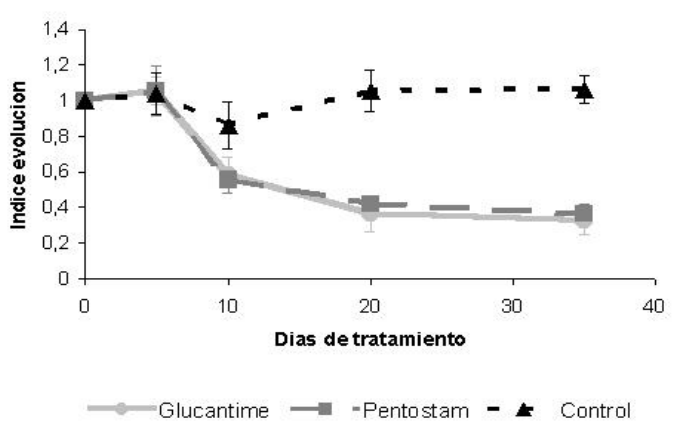

Figura 3. Índice de evolución de hámsteres infectados con $10^{6}$ promastigotes de Leishmania (V.) panamensis MHOM/ COL/84/1099 transfectada con el vector pGL2-aNEO-aLUC (13) que se trataron 3 semanas después con diferentes

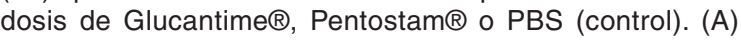
Hámsteres tratados con $30 \mathrm{mg}$ de $\mathrm{Sb} / \mathrm{kg}$ por día por 20días. (B) Hámsteres tratados con $60 \mathrm{mg}$ de SbV/kg por día por 20 días. (C) Hámsteres tratados con $120 \mathrm{mg}$ de Sb/kg por día por 20 días. El índice de evolución se calcula al dividir el tamaño de la lesión en un tiempo determinado $\left(T_{i}\right)$ sobre el tamaño de la lesión antes de iniciar el tratamiento $\left(\mathrm{T}_{0}\right) ; \mathrm{IE}=\left(\mathrm{T}_{\mathrm{i}}\right) /$ $\left(\mathrm{T}_{0}\right)$. 
Cuadro 1. Promedio de niveles séricos enzimáticos de hámsteres infectados con L. panamensis MHOM/COL/84/1099 y tratados con Glucantime® o Pentostam $®$.

\begin{tabular}{|c|c|c|c|c|c|c|c|c|c|}
\hline & \multicolumn{9}{|c|}{$\begin{array}{l}\text { Niveles séricos enzimáticos } \\
\text { Dosis (cada } 24 \text { horas/20 días) }\end{array}$} \\
\hline & \multicolumn{3}{|c|}{$120 \mathrm{mg} \mathrm{Sb} / \mathrm{kg}$} & \multicolumn{3}{|c|}{$160 \mathrm{mg} \mathrm{Sb} / \mathrm{kg}$} & \multicolumn{3}{|c|}{$240 \mathrm{mg} \mathrm{Sb} / \mathrm{kg}$} \\
\hline reatining & g/dl)0,42 & 0,43 & 0,75 & 0,4 & 0,45 & NS & 0,41 & 0,46 & $0,09^{* *}$ \\
\hline AST & 45,67 & 44,00 & 0,44 & 50 & 51 & NS & 38,67 & 59,33 & 0,18 \\
\hline ALT & 78,67 & 68,33 & 0,79 & 88,5 & 90,5 & NS & 46,33 & 77,67 & 0,14 \\
\hline Amilasa & 8253,33 & 9800 & 0,21 & No se realizó & No se realizó & 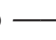 & $8.323,33$ & $8.046,67$ & 0,80 \\
\hline
\end{tabular}

El valor $P$ se estableció en la prueba t de Student con una confiabilidad del $95 \%$.

NS: diferencia no significativa

de luz/segundo) (figura 1). En las muestras de piel se logró detectar la actividad de la enzima luciferasa en 1 parásito/mg de piel, con un punto de corte de 38 cuentas de luz/segundo para piel de animales control no infectados. En las muestras de ganglio, se detectaron hasta 40 parásitos/mg de tejido, con un punto de corte de 54 cuentas de luz/segundo.

Carga parasitaria en la lesión y el ganglio poplíteo después del tratamiento. La cantidad de parásitos persistentes en las lesiones de los hámsteres tratados con la dosis de 60 y $120 \mathrm{mg}$ de $\mathrm{Sb} / \mathrm{kg}$ por día por 20 días de ambos medicamentos fue similar. En los tratados con de $30 \mathrm{mg}$ de antimoniato de meglumina el número de parásitos fue mayor que en los tratados con estibogluconato de antimonio, pero las diferencias no alcanzaron significancia estadística $(p=0,114)$ (figura 4 ).

Ninguno de los esquemas de tratamiento eliminó los parásitos de la totalidad de los hámsteres (figura 4). Al final del tratamiento se detectaron parásitos en la piel de los animales tratados con todas las dosis, con excepción de 3/7 (43\%) hámsteres tratados con Glucantime ${ }^{\circledR}$ y $2 / 7$ (29\%) con Pentostam $®$ correspondientes al grupo de 120 $\mathrm{mg}$ de $\mathrm{Sb}^{\mathrm{V}} / \mathrm{kg}$ por día por 20 días. En el ganglio no se detectaron parásitos después del tratamiento (figura 4).

\section{Toxicidad y efectos colaterales}

No se encontraron diferencias entre los niveles séricos de las enzimas ALT, AST o creatinina en los hámsteres tratados con Pentostam ${ }^{\circledR}$ o Glucantime $₫$ durante 10 días a la dosis de 120 o
$240 \mathrm{mg}$ de $\mathrm{Sb} / \mathrm{kg}$ por día, o durante 20 días con $160 \mathrm{mg}$ de $\mathrm{Sb} \vee / \mathrm{kg}$ por día (cuadro 1). Solamente en $1 / 3$ de los hámsteres tratados con Pentostam $\AA$ o Glucantime ${ }^{\circledR}$ se detectó un aumento en los niveles de ALT. La CK se encontró elevada en los hámsteres tratados con Pentostam ${ }^{\circledR}(160 \mathrm{mg}$ de $\mathrm{Sb} / \mathrm{kg}$ por día por 20 días). Los animales tratados con este producto mostraron mayores signos de dolor que con el Glucantime ${ }^{\circledR}$ durante la administración del mismo. Esto se correlacionó con los hallazgos histopatológicos del músculo esquelético en 2/3 hámsteres tratados con 160 $\mathrm{mg}$ de $\mathrm{Sb} / \mathrm{kg}$ de Pentostam $®$ que revelaron una inflamación mixta de predomino crónico, así como alteraciones de tipo degenerativo. En todos los

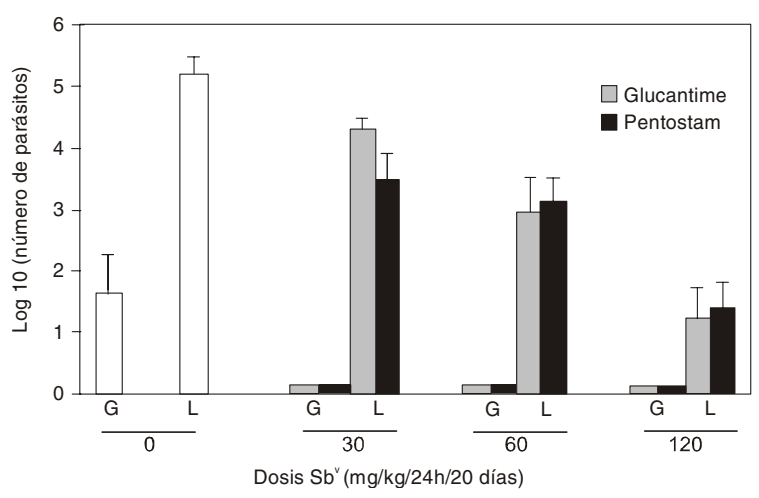

Figura 4. Carga parasitaria determinada por luminometría en la lesión cutánea $(L)$ y ganglio poplíteo $(G)$ de hámsteres infectados con L. panamensis transfectada con el gen reportero de la luciferasa, determinada después del tratamiento diario de los animales por la vía intramuscular con distintas dosis de $\mathrm{Sb}^{\vee}$ durante 20 días. Barras vacías, carga parasitaria en hámsteres control tratados con PBS. 
animales tratados con Glucantime $₫$ se evidenció escaso infiltrado inflamatorio y ninguno presentó alteraciones evidentes en la estructura de las fibras musculares.

\section{Discusión}

Los estudios realizados hasta ahora sobre la respuesta clínica al tratamiento con antimoniales pentavalentes y su relación con la sensibilidad in vitro de los aislamientos, no siempre demostraron una buena correlación $(3,7,15)$. En el presente estudio, el empleo de un modelo animal, en conjunto con una cepa e inóculo definido de Leishmania eliminó algunos factores de confusión como: 1) la respuesta inmune variable del hospedero, 2) el tiempo posinfección, 3) el sitio de la lesión $(4,16,17)$ y la heterogeneidad en la infectividad/patogenicidad de Leishmania (18).

Además, la utilización de un único lote de cada uno de los medicamentos eliminó la comprobada variabilidad en la capacidad leishmanicida y la toxicidad de estos compuestos, atribuida a variaciones en la polimerización de los carbohidratos durante la síntesis de los antimoniales $(7,19)$. Tanto el seguimiento clínico como el parasitológico de los hámsteres tratados con Pentostam $\AA$ o Glucantime $₫$, luego de ser infectados experimentalmente con L. panamensis, fueron similares para ambos compuestos y concuerda con los resultados terapéuticos en humanos a pesar de las variaciones entre los ensayos clínicos ya mencionados $(5,6)$.

La importancia de los ensayos preclínicos en animales experimentales queda demostrada por la dicotomía entre las observaciones in vivo e in vitro. Mientras que ambos medicamentos muestran efectos clínicos similares, el análisis bioquímico sugiere que el estibogluconato de sodio podría ser más activo contra Leishmania debido a que, a diferencia del antimoniato de meglumina y el tartrato de antimonil potásico (Sb"I'), tiene un marcado poder inhibitorio sobre la ADN topoisomerasa $(10,20,21)$.

Además, los ensayos in vivo como en el estudio presente, son esenciales para la evaluación de los antimoniales (y posiblemente son aplicables a otros compuestos) debido a que los resultados obtenidos in vitro carecen del componente farmacocinético y farmacodinámico y los vehículos como el m-clorocresol (Pentostam $®$ ), el bisulfito de potasio y sulfito de sodio anhidro (Glucantime®) pueden modificar el efecto antiLeishmania $(15,22)$.

En nuestro estudio encontramos que a dosis bajas de $\mathrm{Sb}^{\vee}$ el estibogluconato de sodio tendió a eliminar más parásitos que el antimoniato de meglumina y que la toxicidad de los dos productos, determinada por los valores séricos de las enzimas ALT, AST y de creatinina, que indican alteraciones hepáticas o renales, no difirió significativamente de los controles sin tratamiento.

Otros estudios en roedores que usaron dosis de $900 \mathrm{mg}$ de Sbv/kg por día por 30 días, mostraron un aumento significativo en los niveles séricos de ALT, AST y creatinina, pero los resultados a estas dosis altas son de cuestionable extrapolación a la población humana, en la que se emplean dosis mucho más bajas (20 mg de $\mathrm{Sb} \vee / k g$ por día por 20 días) (23).

Cabe señalar que en el modelo hámster, el Pentostam ${ }^{\circledR}$ demostró ser más tóxico que el Glucantime $₫$, por las alteraciones macro y microscópicas producidas en el sitio de la inyección (músculo) y el aumento en los valores de la enzima CK. Esto está de acuerdo con los estudios de Sampaio et al. (24) y Saldanha et al. (25) que encontraron al estibogluconato de sodio más tóxico que el antimoniato de meglumina; se destaca la mayor frecuencia de cefaleas $(p=0,026)$ mialgias/artralgias $(p=0,004)$ y dolor abdominal/anorexia $(p=0,004)$.

La pérdida de infectividad o patogenicidad de los parásitos es un fenómeno frecuente en los estudios de Leishmania que requieren una manipulación prolongada in vitro. Sin embargo, en este estudio la cepa transfectada se mantuvo mediante el pase cíclico por hámster-cultivo en medio selectivo-hámster, lo que finalmente permitió obtener una patogenicidad similar de las cepas silvestre y transfectada.

Así mismo, la sensibilidad de la cepa al $\mathrm{Sb}^{\vee}$ no se vio afectada por el procedimiento de transfección con el plásmido que contenían el gen 
reportero y el gen selectivo de resistencia al antibiótico G418, ya que las lesiones de los infectados con la cepa silvestre y transfectada respondieron de forma similar al tratamiento con $\mathrm{Sb}^{\mathrm{V}}$.

En el presente estudio se confirmó que la luminometría es una técnica cuantitativa, sensible y rápida para determinar la carga parasitaria en los tejidos de animales infectados experimentalmente. Una posible limitación de este método es la necesidad de contar con organismos transfectados, que pueden perder la infectividad o patogenicidad durante la manipulación in vitro, por lo que requiere del pase continuo de los parásitos seleccionados por el hámster.

Las modificaciones metodológicas introducidas en el procesamiento de las muestras permitieron mejorar el sistema publicado para el modelo en ratón (13) y determinar el límite de sensibilidad de la prueba en los tejidos. Encontramos que la luminometría es un método de sensibilidad comparable a la PCR que resulta ser más sencillo, rápido y menos costoso. A diferencia de la PCR, la luminometría detecta exclusivamente parásitos viables debido a la corta vida (2-3 horas) de la proteína sintetizada por el parásito (26). Además, tiene ventajas sobre el método estándar de cultivo, debido a que cuantifica directamente la cantidad de parásitos presentes, evitando el sesgo que introduce el éxito de replicación de los parásitos en cultivo.

En conclusión, nuestros resultados en el modelo hámster no mostraron diferencias significativas en la eficacia clínica y parasitológica del Pentostam ${ }^{\circledR}$ y el Glucantime $®$ para tratar $L$. panamensis, pero indicaron que los efectos tóxicos locales del Pentostam $₫$ son mayores que los del Glucantime ${ }^{\circledR}$. Queda por comprobar en estudios comparativos de campo si los menores efectos tóxicos percibidos por los pacientes tratados con Glucantime ${ }^{\circledR}$ podrían favorecer el cumplimiento del esquema terapéutico recomendado.

\section{Agradecimientos}

Este trabajo se desarrolló con el apoyo financiero de Wellcome Trust-Burroughs (Ref \# 059056/Z/99), Colciencias (contrato 162-2002, código
22290411723) y el programa de jóvenes investigadores de Colciencias. Se agradece al Instituto Nacional de Salud de Colombia) por la gentil donación del Glucantime® y a P. Desjeux (TDR-OMS) por la donación del Pentostam ${ }^{\circledR}$. Se agradece el apoyo de John Walter (Cideim) y Marc Ouellette, Universidad de Laval (Canadá) por la transfección de la cepa MHOM/COL/84/1099.

\section{Referencias}

1. Herwaldt BL, Berman JD. Recommendations for treating leishmaniasis with sodium stibogluconate (Pentostam) and review of pertinent clinical studies. Am J Trop Med Hyg 1992;46:296-306.

2. Chulay JD, Flechenstein L, Smith DH. Pharmacokinetics of antimony during treatment of visceral leishmaniasis with sodium stibogluconate and meglumin antimoniate. Trans R Soc Trop Med Hyg 1988;82:69-72.

3. Grogl M, Thomason T, Franke E. Drug resistance in leishmaniasis: its implications in systemic chemotherapy of cutaneous and mucocutaneous disease. Am J Trop Med Hyg 1992;46:117-26.

4. WHO. WHO expert committee on the control of the leishmaniases. Control of the leishmaniases. World Health Organization technical report series No. 793. Geneva: WHO; 1990.

5. Sáenz RE, Paz HM, Johnson CM, Narváez ER, De Vásquez AM. Evaluación de efectividad y toxicidad del Pentostam ${ }^{\circledR}$ y Glucantime ${ }^{\circledR}$ en el tratamiento de leishmaniasis cutánea. Rev Med Panamá 1987;12: 148-64.

6. Saldanha AC, Romero GA, Mercham-Hammann E, Magalhaes AV, Macedo V de O. Estudo comparativo entre estibogluconato de sodio BP88 e antimoniato de meglumina no tratamento da leishmaniose cutánea I. Eficacia e seguranca. Rev Soc Bras Med Trop 1999;32: 383-7.

7. Jackson JE, Tally JD, Ellis WY, Mebrahtu YB, Lawyer PG, Were JB et al. Quantitative in vitro drug potency and drug susceptibility evaluation of Leishmania ssp. from patients unresponsive to pentavalent antimony therapy. Am J Trop Med Hyg 1990;43:464-80.

8. Callahan HL, Portal AC, Devereaux R, Grogl M. An axenic amastigote system for drug screening. Antimicrob Agents Chemother 1997;41:818-22.

9. Yi T, Pathak MK, Lindner D, Ketterer ME, Farver C, Borden EC. Anticancer activity of sodium stibogluconate in synergy with IFNs. J Immunol 2002;169:5978-85.

10. Walker J, Saravia NG. Inhibition of Leishmania donovani promastigote DNA topoisomerase I and human monocyte DNA topoisomerases I and II by antimonial drugs and classical anti-topoisomerase agents. J Parasitol 2004; (en prensa). 
11. Travi BL, Martínez JE, Zea A. Antimonial treatment of hamsters infected with Leishmania (Viannia) panamensis: assessment of parasitological cure with different therapeutic schedules. Trans R Soc Trop Med Hyg 1993;87:567-9.

12. Naylor LH. Reporter gene technology: the future looks bright. Biochem Pharmacol 1999;58:749-57.

13. Roy G, Dumas C, Sereno D, Wu Y, Singh A, Tremblay $\mathrm{M}$ et al. Episomal and stable expression of the luciferase reporter gene for quantifyng Leishmania spp. Infections in macrophages and in animals models. Mol Biochem Parasitol 2000;110:195-206.

14. Travi BL, Osorio Y, Melby PC, Chandrasekar B, Arteaga L, Saravia NG. Gender is a major determinant of the clinical evolution and inmune response in hamsters infected with Leishmania spp. Infect Immun 2002;70:228896.

15. Robledo SM, Valencia AZ, Saravia NG. Sensitivity to glucantime ${ }^{\circledR}$ of Leishmania (Viannia) isolated from patients prior to treatment. J Parasitol 1999;85:3606.

16. Osorio Y, González SJ, Gama VL, Travi BL. Reinfection in American cutaneous leishmaniasis: evaluation of clinical outcomes in the hamster model. Mem Inst Oswaldo Cruz 1998;93:353-6.

17. Osorio Y, Melby PC, Pirmez C, Chandrasekar B, Guarin N, Travi BL. The site of cutaneous infection influences the immunological response and clinical outcome of hamsters infected with Leishmania panamensis. Parasite Immunol 2003;25:139-48.

18. Sinagra A, Riarte A, Luna C, Campanini A, Segura EL. Leishmania (Viannia) braziliensis: biological behavior in golden hamsters of isolates from Argentine patients. Am J Trop Med Hyg 1997;57:115-8.
19. Steck E. The chemotherapy of protozoan diseases. Second edition. Washington, D.C.: Division of Medicinal Chemistry, Walter Reed Army Institute of Research; 1972. p.79-90.

20. Chakraborty AK, Majumder HK. Mode of action of pentavalent antimonials: specific inhibition of type I DNA topoisomerase of Leishmania donovani. Biochem Biophys Res Commun 1988;152:605-11.

21. Lucumi A, Robledo S, Gama V, Saravia NG. Sensitivity of Leishmania (Viannia) panamensis to pentavalent antimony is correlated with the formation of cleavable DNA-protein complexes. Antimicrobial Agents Chemother 1998;42:1990-5.

22. Roberts WL, Rainey PM. Antileishmanial activity of sodium stibogluconate fractions. Antimicrobial Agents Chemother 1993;37:1842-6.

23. AlKhawajah A, Larbi EB, Jain S, Al-Gindan Y, Abahussain A. Subacute toxicity of pentavalent antimony compounds in rats. Hum Exp Toxicol 1992;11: 283-8.

24. Sampaio RN, De Paula CD, Sampaio JH, Furtado RS, Leal PP, Rosa TT et al. The evaluation of the tolerance and nephrotoxicity of pentavalent antimony administered in a dose of $40 \mathrm{mg} \mathrm{Sb} \mathrm{V/kg/day,} \mathrm{12/12} \mathrm{hr,} \mathrm{for} 30$ days in the mucocutaneous form of leishmaniasis. Rev Soc Bras Med Trop 1997;30:457-63.

25. Saldanha AC, Romero GA, Guerra C, MerchamHamman E , Macedo V de O. Estudo comparativo entre estibogluconato de sodio BP88 e antimoniato de meglumina no tratamiento de leishmaniose cutánea. Toxicidade bioquímica e cardiaca. Rev Soc Bras Med Trop 2000;33:383-8.

26. Carlsen H, Moskaug JO, Fromm SH, Blomhoff R. In vivo imaging of NF-KB activity. J Immunol 2002;168: 1441-6. 